\title{
Thermal endometrial ablation for abnormal uterine bleeding due to endometrial pathology: an alternative to hysterectomy
}

\author{
D L W Dasanayakea, I M R Goonewardene ${ }^{a}$
}

\begin{abstract}
Introduction: Among women of reproductive age Abnormal Uterine Bleeding (AUB) due to a primary endometrial pathology (AUB-E) occurs in up to $25 \%$, and it has a significant adverse impact on their quality of life. In Sri Lanka, hysterectomy continues to be the commonest modality for the treatment of AUB-E not responding to medical therapy. Thermal Endometrial Ablation (TEA) is an alternative option for the management of women with AUB-E.

Objective: To describe the effectiveness, short and long term complications, patient satisfaction and cost of TEA in the management of women with AUB-E in Sri Lankan setting.

Method: Thirty women with AUB-E underwent TEA under regional anaesthesia at the Academic Department of Obstetrics and Gynaecology of the Teaching Hospital Mahamodara, Galle (THMG) during the period of November 2012 to April 2015. Data was collected using an interviewer administrated questionnaire at discharge, two weeks, three, six, 12 and 24 months post procedure. The effectiveness, short and long term complications, patient satisfaction and cost of TEA in the management of women with AUB-E were studied. Abdominal Hysterectomy $(\mathrm{AH})$ was offered for the patients with treatment failure.

Result: Mean age and Body Mass Index of the women were 46 years (SD 4.8) and $25 \mathrm{Kg} / \mathrm{m}^{2}$ (SD 2.3) respectively. Short term minor complications (abdominal cramps, excessive vaginal discharge and vomiting) were observed in three women $(10 \%)$. There were no major complications. At the end of 12 months, almost half the women were amenorrhoeic with an improvement rate of $90 \%$. At the end of the two years seven (23\%) had amenorrhoea and $20(67 \%)$ had reduced per vaginal bleeding. Three women underwent $\mathrm{AH}$ at three, six and 12 months post procedure respectively, due to treatment failure. The approximate cost of an AH was LKR 49,000. The cost of one TEA device and one TEA installation system were LKR 120,000 and LKR 4,500,000 respectively.

Conclusion: TEA was an effective alternative to AH for the treatment of AUB-E, and had no major complications. However, it was more expensive when compared to $\mathrm{AH}$.
\end{abstract}

Key words: thermal endometrial ablation, abnormal uterine bleeding, abdominal hysterectomy

Sri Lanka Journal of Obstetrics and Gynaecology 2020; 42: 68-75

DOI: http://doi.org/10.4038/sljog.v42i2.7943

a Academic Unit of Obstetrics and Gynaecology, Teaching Hospital Mahamodara, Galle, Sri Lanka.

Correspondence: DLWD, e-mail: lanka.dasanayake@yahoo.com

https://orcid.org/0000-0001-9306-6508

Received 20 $0^{\text {th }}$ February 2020

Accepted $14^{\text {th }}$ May 2020 


\section{Introduction}

Abnormal Uterine Bleeding (AUB) has a significant adverse impact on women's quality of life ${ }^{1}$. Women with AUB have been shown to have Health Related Quality of Life (HRQOL) below the $25^{\text {th }}$ centile for the general population ${ }^{2}$. Among women of reproductive age, prevalence of AUB ranges from 10 to $30 \%^{2}$, and it has been estimated that up to $80 \%$ of women who were treated, have AUB due to a primary endometrial pathology (AUB-E) $)^{3,4}$. AUB is one of the commonest reasons for gynaecological outpatient department referrals in the $\mathrm{UK}^{5}$, and it has been estimated that one in five women will have hysterectomy by the age of 55 , mostly for menstruation related problems ${ }^{6}$.

Medical management is the preferred, first line of treatment of AUB-E $E^{7}$. The surgical options available for the treatment of AUB-E can be broadly divided in to: techniques carried out under hysteroscopic control (first generation devices), non hysteroscopic ablation techniques (second generation devices) and hysterectomy. Hysterectomy leads to amenorrhoea in 100\% of women and results in the highest improvement in HRQOL of all the treatment modalities available. However a hysterectomy should not to be embarked on lightly, as it can be associated with serious morbidity or even mortality, as evident from the VALUE study ${ }^{8}$. Although effective in treating AUB-E, first generation techniques (eg. Trans Cervical Resection of Endometrium) have the limitation of needing an experienced surgeon, associated potential fatal complications, a steep learning curve and a need for anaesthesia and hysteroscopy9. These short comings paved the way for the development of second generation devices. Many different methods have evolved over time in an attempt to simplify endometrial ablation and enable it to be performed in an outpatient setting without hysteroscopy. They include Thermal Endometrial Ablation (TEA) described by Singer in $1994^{10}$, Cryotherapy described by Pitroff in $1993^{11}$ and Microwave Endometrial Ablation described by Sharp in $1995^{12}$.

Global endometrial ablation using TEA is an effective, non hormonal, permanent treatment modality for AUB- $\mathrm{E}^{13}$. TEA is also a minimally invasive procedure with significantly reduced post operative morbidity ${ }^{13,14}$. If adequate financial resources can be found, of the currently available second generation methods of endometrial ablation, TEA appears to be the best option in low resource setting ${ }^{15}$. The success rates of TEA were reported to range from $88-91 \%$ in a large multi center, international, collaborative study ${ }^{16}$. Long term results of the same study showed (at 5 years) that $86 \%$ did not need a hysterectomy and $75 \%$ did not need further surgery ${ }^{17}$. It has been suggested that TEA should be an adjunct therapy, and not a replacement for $\mathrm{AH}$. It is also probable that observed increased rate of endometrial ablation may be due to repeat ablations due to failed procedures. Furthermore, the minimal change in hysterectomy rate may be partly explained because hysterectomy follows failed ablations as a gold standard treatment for $\mathrm{AUB}^{18}$.

In Sri Lanka, hysterectomy has been the only option to treat women with failed medical treatment for AUB. Although the initial cost could be high, the minimally invasive procedure TEA would be cost effective in the long term because a hysterectomy involves major surgery under general anaesthesia and requires prolonged hospitalization of the patient, in contrast to TEA which could even be done as a day surgical procedure. Even though the National Guidelines for Sri Lanka mentions TEA as a Grade III recommendation for the management of $\mathrm{AUB}^{19}$, it is still not available in government hospitals. The objective of the current study was to describe the effectiveness, short and long term complications, patient satisfaction and cost of TEA in the management of women with AUB-E.

\section{Materials and method}

A prospective cohort study was carried in the Academic Unit of Obstetrics and Gynaecology of the Teaching Hospital Mahamodara Galle (THMG) during the period of November 2012 to April 2015. Approximately 100 women with AUB-E presented to the gynaecological outpatient clinics of Academic Unit of Obstetrics and Gynaecology of the THMG in 2012. It was estimated that approximately $25-30 \%$ of them would have been suitable for TEA. Accordingly, 30 women with AUB-E were recruited for the study. Inclusion criteria were women with AUB-E, > 30 years of age, and who had no further fertility wishes. Women with active pelvic inflammatory disease, endometrial cavity distorted or elongated more than $15 \mathrm{~mm}$ in its long axis (determined by trans vaginal ultrasound scan), genital tract malignancy, unexplained vaginal bleeding, previous uterine surgery leaving the uterine wall $<8 \mathrm{~mm}$ 
thick, and uterine abnormalities such as septate or bicornuate uteri, were excluded from the study. Informed written consent was obtained from all the women included in the study. Ethical approval was obtained from the Ethical Review Committee, Faculty of Medicine, University of Ruhuna.

The procedure involved TEA with Gynaecare Thermochoice III catheter, Version 3.0 (Gynaecare Worldwide, A division of Ethicon, Inc. A Johnson \& Johnson Company Somerville, New Jersey USA). This has an active mechanism for circulation of 5\% Dextrose within the balloon. A therapy cycle consisted of the circulation of pre heated $5 \%$ Dextrose at $87^{\circ} \mathrm{C}$ for eight minutes. The procedure was carried out under regional anaesthesia. All patients underwent a pre procedure sharp curettage immediately prior to the ablation, to thin the endometrial lining for better effects. The procedure was carried out by trained gynaecologists (specialist or senior registrar or registrar) in the unit. Approximately 30 minutes pre-operatively, $1.5 \mathrm{~g}$ of Cefuroxim and $500 \mathrm{mg}$ of Metronidazole were administered intravenously. Prior to carrying out the procedure, a vaginal examination was carried out to reassess the size and the direction of the uterus. This facilitated the adjustment of the length of the device and direction of insertion.

Post treatment follow up appointments were arranged at two and six weeks, and three, six,12 and 24 months, unless a complication required earlier attention. On discharge, patients were provided a menstrual diary to document frequency and heaviness of menstrual bleeding. At each appointment patients were assessed for their menstrual bleeding pattern and blood loss using the menstrual diary. Satisfaction was assessed using a visual analogue scoring system ranging from $0=$ completely dissatisfied to $10=$ highly satisfied. Patients were informed to report to the outpatient clinic or even get themselves admitted to the unit, at any time if they experienced any troublesome bleeding. The contact telephone number of the Gynaecology Registrar was also provided, to be used in an emergency. If there was no significant improvement of AUB, hysterectomy was offered. The cost of an $\mathrm{AH}$ has been estimated to be approximately LKR 49,00020 .

An ongoing electronic database was maintained confidentially. Outcome measures were calculated as proportions.

\section{Results}

Table 1. Baseline characteristics of the study population $(n=30)$

\begin{tabular}{|l|c|c|c|}
\hline & Range & Mean (SD) & Median \\
\hline Age (years) & $32-53$ & $46.6(4.8)$ & - \\
\hline \multirow{2}{*}{ BMI $\left(\mathrm{kg} / \mathrm{m}^{2}\right)$} & $21.1-29.3$ & $25.0(2.3)$ & - \\
\hline \multirow{2}{*}{ Parity } & \multirow{2}{*}{$0-5$} & IQR & 2 \\
\cline { 2 - 4 } & & $1-3$ & \\
\hline
\end{tabular}

MI = Body Mass Index, SD = Standard Deviation, $\mathrm{IQR}$ = Inter Quintile Range

The basic characteristics of the patients who underwent TEA are shown in Table 1. 
Table 2. Short term complications after thermal balloon ablation

\begin{tabular}{|l|c|c|}
\hline & At one week $(\mathbf{n}=\mathbf{3 0})$ & At discharge $(\mathbf{n}=\mathbf{3 0})$ \\
\hline Excessive nausea and vomiting & 3 & - \\
\hline Abdominal cramps & 3 & 2 \\
\hline Vaginal discharge with 'endometritis' & 2 & 2 \\
\hline
\end{tabular}

There were no major postoperative complications. Short term minor complications (abdominal cramps, excessive vaginal discharge and vomiting) were observed in three women (10\%).

Table 3. Outcome of following thermal balloon ablation

\begin{tabular}{|l|c|c|c|c|}
\hline Outcome & $\begin{array}{c}\text { At three } \\
\text { Months } \\
\text { (n= 30) }\end{array}$ & $\begin{array}{c}\text { At six } \\
\text { Months } \\
\text { (n= 29) }\end{array}$ & $\begin{array}{c}\text { At one } \\
\text { year } \\
\text { (n= 28) }\end{array}$ & $\begin{array}{c}\text { At two } \\
\text { years } \\
\text { (n = 27) }\end{array}$ \\
\hline Amenorrhoea & 5 & 9 & 14 & 7 \\
\hline $\begin{array}{l}\text { Per vaginal bleeding } \\
\text { greatly improved }\end{array}$ & 15 & 15 & 12 & 19 \\
\hline $\begin{array}{l}\text { Per vaginal bleeding } \\
\text { reduced slightly }\end{array}$ & 9 & 4 & 1 & 1 \\
\hline $\begin{array}{l}\text { Per vaginal bleeding } \\
\text { same as previously }\end{array}$ & 1 & 1 & 1 & 0 \\
\hline $\begin{array}{l}\text { Per vaginal bleeding worsened } \\
\text { than previously }\end{array}$ & 0 & 0 & 0 & 0 \\
\hline Hysterectomy & 1 & 1 & 1 & 0 \\
\hline
\end{tabular}

At the end of 12 months, almost half the women were amenorrhoeic with an improvement rate of $90 \%$. At the end of the two years seven (23\%) had amenorrhoea and 20 (67\%) had reduced per vaginal bleeding. Three women underwent $\mathrm{AH}$ at three, six and 12 months post procedure respectively, due to treatment failure (Table 3). 
Table 4. Patient satisfaction after treatment with thermal balloon ablation

\begin{tabular}{|l|c|c|c|c|}
\hline Outcome & $\begin{array}{c}\text { Post Procedure } \\
\text { at 3 Months } \\
(\mathbf{n}=\mathbf{3 0})\end{array}$ & $\begin{array}{c}\text { Post Procedure } \\
\text { at 6 Months } \\
\mathbf{( n = 2 9 )}\end{array}$ & $\begin{array}{c}\text { Post Procedure } \\
\text { at 1 year } \\
\mathbf{( n = 2 8 )}\end{array}$ & $\begin{array}{c}\text { Post Procedure } \\
\text { at 2 years } \\
\text { (n = 27) }\end{array}$ \\
\hline Very satisfied & 4 & 5 & 12 & 17 \\
\hline Adequately satisfied & 18 & 17 & 12 & 9 \\
\hline Slightly satisfied & 5 & 5 & 3 & 1 \\
\hline Unsatisfied & 3 & 2 & 1 & 0 \\
\hline Greatly unsatisfied & 0 & 0 & 0 & 0 \\
\hline
\end{tabular}

Table 4 describes patients satisfaction at different timings following the procedure. Overall satisfaction was high at $90 \%$.

The cost of one device of TEA was LKR 120,000 with cost of installation system of LKR 4,5000,000.

All procedures were performed under regional anaesthesia and mean operating time was 25 minutes (95\% CI 22.6-27.4).

\section{Discussion}

The current study found TEA was an effective alternative with almost half becoming amenorrhic at the end of one year and 90\% showing a marked improvement in their AUB at the end of two years. Since only $10 \%$ required $\mathrm{AH}$ for failure of treatment, short term minor complications were observed in only $10 \%$ of women, no major complications were observed, and overall patient satisfaction was very high, TEA could be considered as an option for treatment of AUB-E in Sri Lanka, in spite of its markedly higher cost compared to $\mathrm{AH}$.

Current study reported higher amenorrhic rate at the end the one year when compared to study done by Muller J et al in 2015 (50\% vs 27\%). They also found that $10 \%$ of hysterectomy rate which was comparable with our findings with their longer follow up time (five years) $)^{21}$.

TEA is recognized to have complications ranging from minor to major consequent to uterine measurements and transferring thermal energy to the uterine cavity. Proper selection of patients for the procedure is of paramount importance to achieve high success rates with minimal complications. It is recognized that a normal sized uterus, a regular endometrial cavity and thinning of the endometrium prior to ablation would enhance the efficacy of treatment. The TEA device has a standard balloon size, which would not be effective for a significantly enlarged or distorted endometrial cavity. Heat generated in a regular endometrial cavity would cause uniform destruction of the endometrium with high success rate while a distorted, irregular endometrial cavity could result in pockets of endometrium not undergoing ablation. A thin endometrium would facilitate complete endometrial ablation. Sharp curettage prior to the procedure was the method used to obtain a thin endometrium prior to ablation. The use of a GnRh analogue was not considered for this purpose due to its higher cost.

Although major complications such as uterine perforation, endometritis, heat damage to bowel, and systemic infection were not seen and short term minor complications were observed in only $10 \%$ of women, the safety of TEA can not be inferred by the current small study. The high patient satisfaction was probably due to the improvement of AUB, short hospital stay and minimal complications.

Although hysterectomy has traditionally been frequently regarded as the definitive modality of treatment for AUB-E, global endometrial ablations have become increasingly popular as a less invasive alternative to $\mathrm{AH}$, over last two decades. Consequently, the number 
of hysterectomies in the UK are reported to have declined by 64\% between 1995 to $2002^{22}$.

The success rates observed in the current study are comparable with other studies reported in the literature ${ }^{16,10}$. In the current study, three (10\%) women underwent hysterectomy due to treatment failure. A systematic review of TEA carried out in 2004 found that 1 to $10 \%$ of patients had hysterectomy at end of one year after TEA, and this number increased to $3 \%$ to $12 \%$ at the end of two years. One study reported that $6 \%$ of patients who had TEA needed a hysterectomy by end of three years, and this figure increased to $9 \%$ at the end of five years ${ }^{23}$.

Second generation techniques have been associated with shorter operative time and being more often performed under local anaesthesia (LA) rather than general aneasthesia $(\mathrm{GA})^{24}$. The development of newer (second generation) endometrial ablative techniques has enabled clinicians to set up a comprehensive outpatient service to treat heavy menstrual bleeding effectively without the need for general anaesthetic or conscious sedation ${ }^{25}$. Furthermore, a study done by Thomas J C et al reported a $80 \%$ success rate of TEA as an outpatient procedure carried out under $\mathrm{LA}^{26}$. The current study was carried out under regional anaesthesia and the operative time was approximately 25 min. which is relatively shorter than the average time taken for the AH. It has been suggested that the learning curve for competency in the TEA procedure involves about 10 cases. The experience of the surgeon and ability of performance under LA would no doubt improve patient satisfaction. Two studies done in two different settings by Jarrell A and Ingrid A A found $54 \%$ and $80 \%$ of women reporting overall satisfaction with the procedure respectively ${ }^{27,28}$. The current study has much higher satisfaction rate $(90 \%)$ with comparison to those studies. Ayesha $\mathrm{A}$ et al also reported in their study on audit of outcomes and patient satisfaction in outpatient endometrial ablation in 2020, as $90 \%{ }^{29}$. If further studies demonstrate the safety of the procedure and the feasibility of carrying it out under LA, it could be carried out as an outpatient procedure and patient satisfaction may also be improved.

Although, in the current study, treatment of AUB-E with TEA was markedly more expensive than treatment with AH. A systematic revive involving 1561, number of countries found that a TEA was markedly cheaper than carrying out $\mathrm{AH}^{30}$. Same finding was reported by Miller JD et al in 2018 for cost effectiveness of endometrial ablation with the Global Ablation Modalities including TEA and hysterectomy for treatment of abnormal uterine bleeding. They found that the cost for hysterectomy was almost double the cost for endometrial ablation ${ }^{31}$. This probably reflects a marked disparity in setting up a TEA system in Sri Lanka compared to European countries.

The main strength of the current study was the well planned follow-up of women up to two years with no loss to follow-up. However, this was only a pilot study and had its limitations. Authors acknowledged the delay of submitting the original article six years after the intervention. This is partly explained due to necessity of carrying out two years of follow up to improve of the quality of the study. The last case recruitment took place in April 2015 and the follow up ended in April 2017. However it took another six months to trace them in community due to changing their residents and contact details. Analysis and report writing were carried out up to one year. However authors believe that this single center experience was still important to low resource setting countries like Sri Lanka due to two main reasons: making decisions to practice minimally invasive interventions, despite of its cost for the postgraduate training purposes and improve the HRQOL of women. Up-to-date there are no Sri Lankan literature available on this regard despite of wide usage of endometrial ablation elsewhere in the world.

The main outcome measure which was menstrual blood loss was assessed only in a semi-objective manner with the maintenance of a menstrual diary by the women. This could lead to inaccuracies. However $50 \%$ became amenorrheic at the end of the two years. Another limitation was the non measurement of pre procedure and post procedure menstrual blood loss to enable a comparison between the two. The study sample was too small and had no power to assess complications adequately. Furthermore, the HRQOL for TEA was not assessed. Proper calculation of cost effectiveness using the absolute cost, duration of hospital stay, procedure related complications and patient satisfaction would have improved the understanding of cost effectiveness of TEA in comparison to conventional AH. "Comparison of cost effectiveness and HRQOL of women who undergo thermal endometrial ablation vs AH" could be the topic for a future study. 
Although its high cost will limit widespread use, TEA an other minimal access gynecological procedures should be made available in teaching centers in order to train postgraduates in the use of these new techniques as well as expose undergraduates to the newer modalities of minimal access gynaecological care.

\section{Conclusion}

TEA was an effective alternative to $\mathrm{AH}$ for the treatment of AUB-E, and had no major complications. However, it was more expensive than $\mathrm{AH}$.

\section{References}

1. Kadir RA, Edlund N, Von Mackensen S. The impact of menstrual disorders on quality of life. Int J Gynaecol Obstet; 113: 3-13.

2. Liu Z, Doan QV, Blumenthal P, et al. A systematic review evaluating health related quality of life, work, improvement of health care costs and utilization in abnormal uterine bleeding. Value Health 2007; 10: 183-94.

3. Hurskainen R, Grenmann S, Komi I, et al. Diagnosis and treatment of menorrhagia. Acta Obstet Gynecol Scand. 2007; 86: 749-57.

4. Lethaby A. Irvine GA, Camerone IT. Cyclical progesterones for heavy menstrual bleeding. Cochrane Database System Review. 2008: CD001016.

5. Conlter A, et al. Outcomes of referrals to gynaecology out patients clinics for menstrual problems: An audit of general practice. Br J Obstet Gynaecol. 1991; 98: 789-96.

6. Vessey MP, Villard Mackintosh L, McPherson K, Coultera A, Yeates D. The epidemiology of hysterectomy: Finding in the large cohort study. Br J Obstet Gynaecol. 1992; 99: 402-7.

7. Julia Osei and Hilary, Critchley, Menorrhogia, mechanisms and targeted therapies, Curr Opin Obstet Gynecol. 2005; 17: 411-18.

8. McPherson K, et al. Severe complications of hysterectomy: The value study. Br J Obstet Gynaecol. 2004; 111: 688-94.

9. Halt EMG. Endometrial resection: Baillers clinical Obstetrics and Gynaecology. 1995; 9: 279-97.

10. Neuwirth RS1, Duran AA, Singer A, MacDonald
R, Bolduc L. The endometrial ablator: a new instrument. Obstet Gynecol. 1994; 83(5): 792-6.

11. Pitroff R, Majia S, Murray A. Initial experience with transcervical cryoablation using saline as a uterine distension medium. Minim Invasive Ther. 1993; 2: 69-73.

12. Sharp NC, Cronin N, Feldberg I, Evans M, Hodgson D, Ellis S. Microwaves for menorrhagia: a new fast technique for endometrial ablation. Lancet. 1995; 346(8981): 1003-4.

13. Dwyer N, Huttory J, Stirrat GM. Randomized controlled trial comparing endometrial resection with abdominal hysterectomy for the surgical treatment of menorrhagia. Br J Obstet Gynaecol. 1993; 100: 237-43.

14. Pinion S, et al. Randomized trial of hysterectomy, endometrial ablation for dysfunctional uterine bleeding. Br Med J. 1994; 309: 979-83.

15. Haththotuwa R, et al. Management of abnormal uterine bleeding in low and high resource setting: Consideration of cultural issues. Semin Reprod Med. 2011; 29(5): 446-58.

16. Amso NN, et al. Uterine thermal balloon therapy for the treatment of menorrhagia: First 300 patient from multicentric study. International collaboration utering balloon working group. Br J Obstet Gynaecol. 1998; 105: 517-23.

17. Amso NN, et al. Uterine endometrial balloon therapy for the treatment of menorrhagia: Long term multicentric follow up study. International collabarotion uterine balloon working group, Hum Reprod. 2003; 18: 1082-7.

18. Farquhar CM, Naoom S, Steiner CA. The impact of endometrial ablation on hysterectomy rates in women with benign uterine conditions in the United States. Int J Technol Assess Health Care.18(3): 625-34.

19. Guideline on the Management of Abnormal uterine bleeding. Sri Lanka College of Obstetricians and Gynaecologists 2007.

20. Ekanayake C, Pathmeswaran A, Kularatna S, et al. Cost evaluation, quality of life and pelvic organ function of three approaches to hysterectomy for benign uterine conditions: Trials 18, 565 (2017) doi:10.1186/s13063-017-2295-7.

21. Patient satisfaction and amenorrhea rate after endometrial ablation by ThermaChoice III or 
NovaSure: a retrospective cohort study I. Muller \& J. van der Palen \& D. Massop-Helmink \& R. Vos-de Bruin \& J. M. Sikkema Gynecol Surg. 2015; 12: 81-7.

22. Peter C Reid, Faizah Mukri. Trends in number of hysterectomies performed in England for menorrhagia: examination of health episode statistics, 1989 to 2002. Br Med J. 2005; 330: 938.

23. Medical Advisory Secretariat. “Thermal balloon endometrial ablation for dysfunctional uterine bleeding: an evidence-based analysis”. Ontario health technology assessment series. 2004; 4(II): 1-89.

24. Bofill Rodriguez M, et al. Endometrial resection and ablation techniques for heavy menstrual bleeding. Cochrane Database of Systematic Reviews 2019, Issue 1. Art. No.: CD001501. DOI: 10.1002/14651858.CD001501.pub5.

25. Reinders I, Geomini P, Timmermans A, de Lange $\mathrm{M}$, Bongers $\mathrm{M}$. Local anaesthesia during endometrial ablation: a systematic review. International Journal of Obstetrics \& Gynaecology 2016; 124 : 190-99.a

26. Thomas JC, Janesh KG. Outpatient thermal balloon ablation of the endometrium. Fertility and Sterility 2004; 82(5); 1395-401.

27. Jarrell A, Olsen ME. Patient satisfaction with thermal balloon endometrial ablation. A retro- spective review. (PMID: 12971146) J Reprod Med. 2003; 48(8): 635-6.

28. Ingrid AA, et al. Efficacy and satisfaction rate comparing endometrial ablation by rollerball electrocoagulation to uterine balloon thermal ablation in a randomised controlled trial. Eur J Obstet Gynecol Reprod Biol. 2004; 114 (1): 97-103.

29. Ajmi A, Das S (2020): Outpatient endometrial ablation: audit of outcomes and patient satisfaction, Journal of Obstetrics and Gynaecology, DOI:10.1080/01443615.2019. 1700945 To link to this article: https://doi.org/10.1080/ 01443615.2019.1700945

30. Garside K, Stein K, Wyatt A, Round A, Price A. The effectiveness and cost-effectiveness of microwave and thermal balloon endometrial ablation for heavy menstrual bleeding: a systematic review and economic modeling. Southampton (UK): NIHR Journals Library; 2003.

31. Miller JD, Lenhart GM, Bonafede MM, et al. Cost effectiveness of endometrial ablation with the NovaSure ${ }^{\circledR}$ system versus other global ablation modalities and hysterectomy for treatment of abnormal uterine bleeding: US commercial and Medicaid payer perspectives. International Journal of Women's Health. 2015; 7: 59-73. DOI: 10.2147/ ijwh.s75030. 